\title{
Effectiveness of AR Books on "Calligraphy with Parallel Pens" towards the Pre-service Teachers' Capability of Instructional Media
}

\author{
Nuttaphong Kanchanachaya and Kanita Nitjarunkul
}

\begin{abstract}
The purposes of this study were to (1) create the AR books on hand lettering calligraphy with parallel pens; (2) examine the usage effect on the pre-service teachers' production capability of instructional media; and (3) investigate the satisfaction level towards the AR books. The sample comprised 123 pre-service teachers who were enrolled in Educational Technology and Innovation. Data collection utilized the following research instruments: (1) The AR books on hand lettering calligraphy with parallel pens; (2) A test form of instructional media production capability; and (3) A survey on pre-service teachers' satisfaction towards the AR books. The data was analyzed in percentage, mean, standard deviation, and t-test.

The findings suggested that 1) the AR books on hand lettering calligraphy with parallel pens were created with high quality at a mean score of 4.45 whereas the E1/E2 efficiency scores were also as high as 83.95 and 82.57 , respectively; 2) the use of the AR books enhanced the production capability of instructional media with .05 significance level when compared to the traditional method used by the control group; and 3) the pre-service teachers were the highest level satisfied to AR books with a mean satisfaction score of 4.53 .
\end{abstract}

Index Terms-Augmented-reality technology, augmented-reality book, instructional media production, hand lettering calligraphy capability.

\section{INTRODUCTION}

Today, technology is introduced and applied to education to enhance and modernize the teaching management. It encourages learners to participate more in learning activities and allows them to learn following their own pace. This is in concert with a paradigm that aims to train the learners to autonomously seek knowledge. The use of technology has led to a shift of learning approach from a very traditional one to a learner-centered one. Nowadays, almost every level of education pays attention to learners, an approach that is known as child-centered education. The teaching management encourages student's participation so instead of taking a passive role as a listener or notetaker, the students would now join an activity or interact with their classmates. Therefore, learning typically occurs through a direct experience from an actual practice. In addition, such atmosphere also encourages in-class freedom of expression where self-confidence can be built up, learning can occur through a new experience, and

Manuscript received May 30, 2018; revised May 30, 2018. This work was supported in part by Faculty of Education, Prince of Songkla University.

The authors are with the Department of Educational Technology, Faculty of Education, Prince of Songkla University, Thailand (e-mail: kanchanachaya@gmail.com,nkanita52@gmail.com). diverse skills can be enhanced.

All Bachelor of Education programs require pre-service teachers to take different courses on instructional media production and Educational Technology and Innovation is one of these. Hand lettering calligraphy with parallel pens a lesson section under a chapter called Graphic Design for Media (Calligraphy Practice with Parallel Pens) in 263-201 Educational Technology and Innovation. The lesson takes two hours and the lesson elements include calligraphy exercises, lecture, demonstration, action, presentation, and assessment. This lesson aims to establish foundation skills for basic graphic design for media.

Hand lettering with parallel pens is one of the calligraphy techniques that can be applied to create various instructional media including word cards, sentence stripes, image captions, etc. Parallel pens come with different size options which make it convenient to prepare the equipment, craft the work, and implement the product [1] [2].

Today's courses on instructional media production tend to focus on practices to meet the course objectives however, they fail to offer creativity-related trainings. Creativity is an essential mix-and-match skill for media design [3] It is crucial to point out that instructional media play a vital role in teaching management in the education system as they act as a medium that can effectively transfer the knowledge, content, experience from teacher to learner [4]. Being that crucial, educational institutions must prioritize and accelerate the development of effective instructional media. The currently found obstacles include inadequate presence of media product when compared to course demands; physical media are prone to damage; media lack of completeness to fulfill the knowledge transfer; media are outdated; teacher's self-created media are substandard and unattractive; media lack of diversity; teachers are unequipped with necessary production skills; media selection is inappropriate; classrooms are not ready for media utilization; etc. [5].

This study was inspired by a new technology called augmented reality as the researcher believed that it could be applied in teaching development. Augmented reality is a technology that adds the 2D or 3D virtual world to the real world through a computerized artificial insert, a.k.a. augmentation. A user can see the information of the virtual world augmented into the real world through a digital camera of a tablet, smartphone, or any other equivalent device which offers real-time perceptual information [6]. In addition, augmented reality is potentially useful in many aspects of work development for instance, it can be used to create new learning experiences and promote even more successful 
learning outcomes. Augmented reality is a form of media that can bring abstract knowledge to reality with possible direct media interaction in a virtually augmented world. Its dynamic presentation can simulate movements that allow learners to enjoyably interact with the digital content [7]. The current trend indicates that augmented reality has now played more roles in everyday life for the fact that it can be used in medical, business, entertainment, advertising, and educational industries. Moreover, learning can be made more attractive and complex content can be made easier to digest and comprehend. Another advantage of augmented reality is that it is a form of media that allows learners to autonomously spend the time on as needed.

There are many applications that facilitate the creation and use of augmented reality e.g. Aurasma, Zoobrust, Layar, ColarMix, Junaio, Unity 3D, and etc. Through these applications, teachers or educational technologists can create a $2 \mathrm{D}$ or $3 \mathrm{D}$-image or video content, add the content to the application, and utilize it. However, it may currently be quite difficult to find available Thai content, a preferred and optimal type of content for the teaching management context of this study and as required by the Bachelor of Education programs aiming to produce teachers. For that reason, the researcher took a particular interest in what the effect of the augmented-reality books (AR books) on hand lettering calligraphy with parallel pens would have towards the pre-service teachers' production capability of instructional media. The implementation would offer an opportunity for the pre-service teachers to improve the calligraphy skill which can be handy for an instructional media creation, a key element of graphic design for instructional media. Augmented-reality was incorporated in the media creation as vast number of applications support the technology. In addition, the use of the technology is uncomplicated and extensively applicable to a wide variety of usage.

\section{OBJECTIVE}

1) To create the AR books on hand lettering calligraphy with parallel pens;

2) To examine the usage effect on pre-service teachers' production capability of instructional media after using the AR books;

3) To investigate the satisfaction level of the pre-service teachers after using the AR books.

\section{HYPOTHESIS}

1) Pre-service teachers, who learn from the $A R$ books on hand lettering calligraphy with parallel pens to create an instructional media as the experimental group, were able to produce the media more effectively than that of the control group;

2) The pre-service teachers feel the highest level satisfied to use the AR books on hand lettering calligraphy with parallel pens.

\section{SCOPE POPULATION AND SAMPLE}

\section{A. Population}

The population of this study was the 131,020 pre-service teachers who were enrolled in the undergraduate programs, of Education, Thailand [8].

\section{B. Sample}

The sample comprised 123 pre-service teachers who took the Educational Technology and Innovation course. Through simple random sampling, the experimental group of 69 pre-service teachers studied with the AR books on hand lettering calligraphy with parallel pens whereas the control group of 54 pre-service teachers studied by traditional method.

\section{CONTENT}

There were four AR book series on hand lettering calligraphy with parallel pens namely, Basic Calligraphy; Thai Calligraphy; English Calligraphy; and Arabic Calligraphy.

Variables

1) Independent variable: Studying hand lettering calligraphy with parallel pens through the AR books vs traditional method;

2) Dependent variable: (1) The production capability of instructional media and (2) the satisfaction level.

\section{INSTRUMENTS}

1) AR books on hand lettering calligraphy with parallel pens (Fig. 1);

2) A test form of instructional media production capability;

3) A survey on pre-service teachers' satisfaction towards the AR books on hand lettering calligraphy with parallel pens.

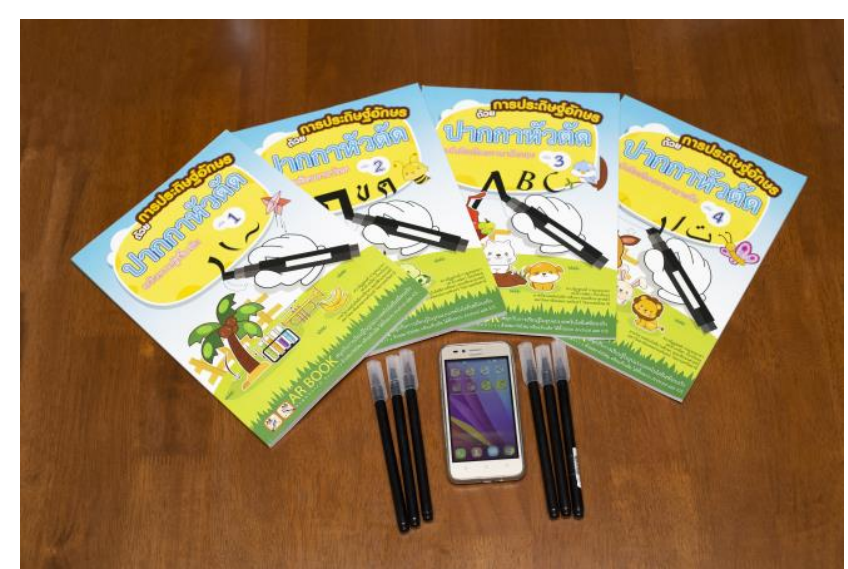

Fig. 1. AR books on "Hand Lettering Calligraphy with Parallel Pens".

\section{METHODOLOGY}

This is an experimental study with the following work sequence:

1) A review of literature, research, document, textbook, and data relevant to creating the AR books on hand lettering calligraphy with parallel pens;

2) A development of the four AR books on hand lettering calligraphy with parallel pens which include Basic Calligraphy;Thai Calligraphy; English Calligraphy; and 
Arabic Calligraphy (Fig. 2);

3) A quality assessment of the AR books by the experts;

4) An efficiency assessment of the AR books by the pre-service teachers who were enrolled in Educational Technology and Innovation;

5) A development test form of instructional media production capability as well as evaluation criteria on the capability of instructional media production. The evaluation criteria include the line quality (sharpness), shape and size of the letters, correctness in writing according to the lettering patterns, letter spacing and cleanliness (scratching, crossing, erasing, and striking);

6) A validation on item-objective congruence (IOC) of the measurement;

7) A development of the satisfaction survey enquiring data on pre-service teachers' satisfaction towards the AR books on hand lettering calligraphy with parallel pens;

8) A validation on item-objective congruence (IOC) of the survey;

9) An experiment on the sample group through three study phases: pre-, during-, and post-experiment

10)A summary, analysis and result discussion

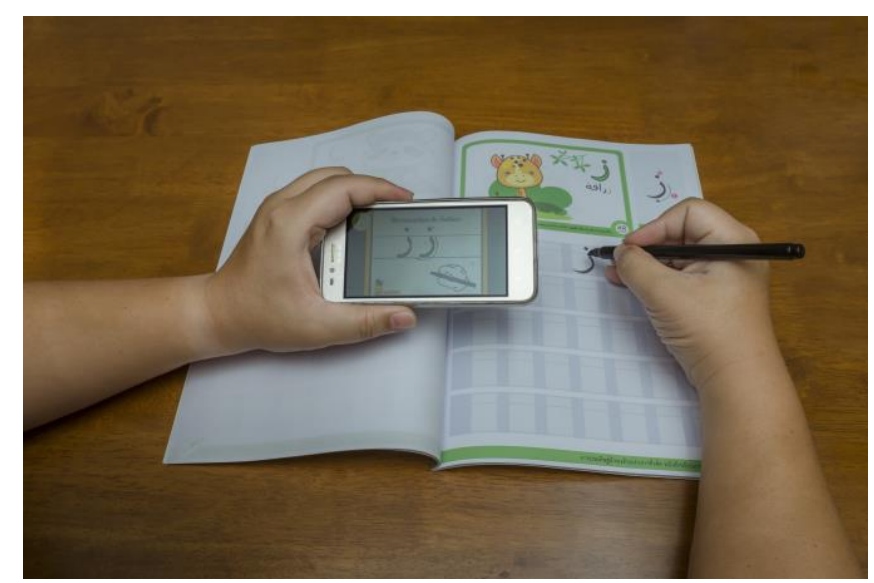

Fig. 2. Development of AR books on "Hand Lettering Calligraphy with Parallel Pens".

\section{DATA ANALYSIS}

Statistical analysis in this study includes mean $(\overline{\mathrm{x}})$, standard deviation (SD), T-test of independent-samples, and T-test of dependent-samples.

\section{Results}

The effect of the books on the production capability can be summarized as follows:

1) The overall quality assessment of the AR books was good with a mean score of 4.45. Breaking down into dimensions, the quality assessment yielded the following results: The quality of format arrangement; image organization; and content were very good with $4.65,4.66$, and 4.66 mean scores, respectively whereas the quality of voice narration and sound effect; animation; and usage were good with $4.14,4.38$, and 4.18 mean scores, respectively (Table I). After the assessment, some quality adjustments including voice narration, sound effect, and animation modifications were done pursuant to the suggestions from the experts;
TABLE I: QUALITY ASSESSMENT RESULTS FROM THE EXPERTS ON THE AR BoOKS ON "Hand LetTering Calligraphy With Parallel Pens" towards Pre-service Teachers' Production CAPability of INSTRUCTIONAL MEDIA

\begin{tabular}{lccc}
\hline $\begin{array}{c}\text { Dimensions for Quality } \\
\text { Assessment }\end{array}$ & $\overline{\mathbf{x}}$ & S.D. & Quality Level \\
\hline \hline $\begin{array}{l}\text { 1. Quality of format } \\
\text { arrangement }\end{array}$ & $\mathbf{4 . 6 5}$ & $\mathbf{0 . 4 9}$ & Very good \\
$\begin{array}{l}\text { 2. Quality of image } \\
\text { organization }\end{array}$ & $\mathbf{4 . 6 6}$ & $\mathbf{0 . 4 7}$ & Very good \\
$\begin{array}{l}\text { 3. Quality of content } \\
\begin{array}{l}\text { 4. Quality of voice } \\
\text { narration and sound } \\
\text { effect }\end{array}\end{array}$ & $\mathbf{4 . 6 6}$ & $\mathbf{0 . 4 9}$ & $\begin{array}{c}\text { Very good } \\
\text { Good }\end{array}$ \\
$\begin{array}{l}\text { 5. Quality of animation } \\
\text { 6. Quality of Usage }\end{array}$ & $\mathbf{4 . 1 4}$ & $\mathbf{0 . 7 0}$ & \\
& 4.38 & $\mathbf{0 . 5 2}$ & $\begin{array}{l}\text { Good } \\
\text { Good }\end{array}$ \\
\hline
\end{tabular}

Later on, the researcher conducted an efficiency assessment of the AR books on their effects towards the pre-service teachers' production capability of instructional media. The AR books were used in an experiment on a group that was characteristically similar to the experimental group. The experiment was conducted in 1:1- (3 people); small-group (9 people); and large group (30 people) patterns involving the pre-service teachers who enrolled in Educational Technology and Innovation in semester 2/2015. The pre-service teachers tried the developed AR books on hand lettering calligraphy with parallel pens and the production capability of instructional media was measured before (E1) and after (E2) the learning. The efficiency assessment results suggested that the production capability scores during and after the learning were $83.95 \%$ and $82.57 \%$, respectively. The E1/E2 efficiency scores of 83.95/82.57 exceeded the $80 / 80$ target criteria and therefore indicated that the AR books on hand lettering calligraphy with parallel pens sufficiently passed the target efficiency criteria (Table II).

TABLE II: EFFICIENCY ASSESSMENT RESUlts By THE STUdENT GROUP THAT USED THE AR BOOKS ON "HAND LETTERING CALligRAPHY WITH PARALlel PENS" AND Their PRODUCTION CAPABILITy OF INSTRUCTIONAL MEDIA

\begin{tabular}{lcc}
\hline \multicolumn{1}{c}{ Learning } & Efficiency & Efficiency Criteria \\
\hline \hline $\begin{array}{l}\text { During-learning } \\
\text { assessment (E1) }\end{array}$ & $\mathbf{8 3 . 9 5}$ & $\mathbf{8 0}$ \\
Post-learning & & $\mathbf{8 0}$ \\
assessment (E2) & $\mathbf{8 2 . 5 7}$ & \\
\hline
\end{tabular}

2) Pre-service teachers who were enrolled in 263-201 Educational Technology and Innovation were divided into two groups: The experimental group of 69 students who used the AR books on hand lettering calligraphy with parallel pens in their class; and the control group of 54 pre-service teachers who studied in a traditional way. The comparative results suggested the following capability data:

- The pre-learning capability on instructional media production of both groups were found with no significant difference at the .05 level i.e. the control group had a mean score of 14.19 and a standard deviation value of 0.953 whereas the experimental group had a mean score of 14.07 and a standard 
deviation value of 1.386 (Table III).

TABLE III: PRE-LEARNING CAPABILITY SCORE COMPARISON BETWEEN THE CONTROL AND EXPERIMENTAL GROUP ON INSTRUCTIONAL MEDIA Production In HAND LETtering CALligraphy WITH PARAllel PENS

\begin{tabular}{lccccc}
\hline $\begin{array}{c}\text { Pre-learning } \\
\text { Capability }\end{array}$ & $\mathbf{n}$ & $\overline{\mathbf{x}}$ & S.D. & $\mathbf{t}$ & Sig. \\
\hline \hline Control group & $\mathbf{5 4}$ & $\mathbf{1 4 . 1 9}$ & $\mathbf{0 . 9 5 3}$ & $\mathbf{0 . 5 1 0}$ & $\mathbf{0 . 6 1 1}$ \\
$\begin{array}{l}\text { Experimental } \\
\text { group }\end{array}$ & 69 & $\mathbf{1 4 . 0 7}$ & $\mathbf{1 . 3 8 6}$ & & \\
\hline
\end{tabular}

- 2.2 The post-learning capability on instructional media production of the control group were found higher than the pre-learning capability with significant difference at the .05 level i.e. during the pre-learning period, the control group had a mean score of 14.19 and a standard deviation value of 0.953 whereas during the post-learning period, the mean score was 17.50 with standard deviation value of 1.194 (Table IV).

TABLE IV: CAPABILITY SCORE COMPARISON OF THE CONTROL GROUP BETWEEN THE PRE-LEARNING AND POST-LEARNING PERIOD ON InSTRUCTIONAL MEDIA PRODUCTION IN HAND LETTERING CALligraPhy WITH PARALLEL PENS

\begin{tabular}{lccccc}
\hline \multicolumn{1}{c}{ Control Group } & $\mathbf{n}$ & $\overline{\mathbf{x}}$ & S.D. & $\mathbf{t}$ & Sig. \\
\hline \hline Pre-learning & 54 & 14.19 & $\mathbf{0 . 9 5 3}$ & 109.37 & $\mathbf{0 . 0 0 0}$ \\
Post-learning & 54 & 17.50 & 1.194 & & \\
\end{tabular}

- The post-learning capability on instructional media production of the experimental group were found higher than the pre-learning capability with significant difference at the .05 level i.e. during the pre-learning period, the experimental group had a mean score of 14.07 and a standard deviation value of 1.386 whereas during the post-learning period, the mean score was 20.90 with standard deviation value of 1.467 (Table V).

TABLE V: CAPABILITY SCORE COMPARISON OF THE EXPERIMENTAL GROUP BetWeEN THE PRE-LEARNING AND POST-LEARNING PERIOD ON Instructional Media Production in Hand LetTering CALligraphy WITH PARALLEL PENS

\begin{tabular}{lccccc}
\hline $\begin{array}{c}\text { Experimental } \\
\text { Group }\end{array}$ & n & $\overline{\mathbf{x}}$ & S.D. & t & Sig. \\
\hline \hline Pre-learning & 69 & 14.07 & 1.386 & 84.336 & $\mathbf{0 . 0 0 0}$ \\
Post-learning & 69 & 20.90 & 1.467 & & \\
\end{tabular}

- The post-learning capability on instructional media production of the experimental group was found higher than that of the control group with significant difference at the .05 level i.e. the control group had a mean score of 17.50 and a standard deviation value of 1.194 whereas the experimental group had a mean score of 20.90 and a standard deviation value of 1.467 (Table VI).

3) 69 pre-service teachers in the experimental group indicated the highest level satisfaction level $(x=4.53)$ towards studying hand lettering calligraphy with parallel pens through the use of AR books which affected their capability in producing instructional media. Further dimensional analysis provided the following insights: The dimensions with highest satisfaction comprised "appropriateness of the video"; "convenience and speed of video data access"; "usage responsiveness", and "general evaluation" with 4.78, 4.58, 4.70, 4.55 mean scores, respectively. The dimensions with high satisfaction comprised "completeness of the presented data"; "efficiency in utilization"; "modernity and usage simplicity"; and "beauty of book format" with 4.43, 4.39, 4.41 , and 4.38 mean scores, respectively (Table VII ).

TABLE VI: POST-LEARNING CAPABILITY SCORE COMPARISON BETWEEN THE CONTROL AND EXPERIMENTAL GROUP ON INSTRUCTIONAL MEDIA PRoduction IN HAND LETTERING CALligraphy With PARALlEL PENS

\begin{tabular}{lccccc}
\hline $\begin{array}{c}\text { Post-learning } \\
\text { Capability }\end{array}$ & $\mathbf{n}$ & $\overline{\mathbf{x}}$ & S.D. & $\mathbf{t}$ & Sig. \\
\hline \hline Control group & $\mathbf{5 4}$ & $\mathbf{1 7 . 5 0}$ & $\mathbf{1 . 1 9 4}$ & $\mathbf{- 1 3 . 8 2}$ & $\mathbf{0 . 0 0 0}$ \\
Experimental group & $\mathbf{6 9}$ & $\mathbf{2 0 . 9 0}$ & $\mathbf{1 . 4 6 7}$ & & \\
\hline
\end{tabular}

TABLE VII: SATISFACTION LEVEL OF THE PRE-SERVICE TEACHERS TOWARDS STUDYING HAND LETTERING CALLIGRAPHY WITH PARALlEL PENS THROUGH THE USE OF AR BOOKS WHICH AFFECTED THEIR CAPABILITY IN PRODUCING INSTRUCTIONAL MEDIA

\begin{tabular}{lccc}
\hline \multicolumn{1}{c}{ Survey Items } & $\overline{\mathbf{x}}$ & S.D. & $\begin{array}{c}\text { Satisfaction } \\
\text { Level }\end{array}$ \\
\hline \hline $\begin{array}{l}\text { 1. Completeness of } \\
\text { presented data }\end{array}$ & $\mathbf{4 . 4 3}$ & $\mathbf{0 . 6 5 3}$ & High \\
$\begin{array}{l}\text { 2. Appropriateness of } \\
\text { the video }\end{array}$ & $\mathbf{4 . 7 8}$ & $\mathbf{0 . 4 1 5}$ & Highest \\
$\begin{array}{l}\text { 3. Efficiency in } \\
\text { utilization }\end{array}$ & 4.39 & $\mathbf{0 . 6 6 9}$ & High \\
$\begin{array}{l}\text { 4. Modernity and usage } \\
\text { simplicity }\end{array}$ & $\mathbf{4 . 4 1}$ & $\mathbf{0 . 5 7 7}$ & High \\
$\begin{array}{l}\text { 5. Beauty of book } \\
\text { format }\end{array}$ & $\mathbf{4 . 3 8}$ & $\mathbf{0 . 7 0 9}$ & High \\
$\begin{array}{l}\text { 6. Convenience and } \\
\text { speed of video data } \\
\text { access }\end{array}$ & $\mathbf{4 . 5 8}$ & $\mathbf{0 . 6 0 4}$ & Highest \\
$\begin{array}{l}\text { 7. Usage } \\
\text { responsiveness }\end{array}$ & & & Highest \\
$\begin{array}{l}\text { 8. General evaluation } \\
\text { Overall }\end{array}$ & $\mathbf{4 . 7 0}$ & $\mathbf{0 . 4 6 4}$ & Highest \\
\hline
\end{tabular}

\section{Discussions}

1) The four AR books on hand lettering calligraphy with parallel pens, which include Basic Calligraphy; Thai Calligraphy; English Calligraphy; and Arabic Calligraphy, were assessed for quality and efficiency on pre-service teachers' capability of instructional media production. The experts indicated the overall quality of the AR books were good with a mean score of 4.45 . The AR books also received higher efficiency scores $(\mathrm{E} 1 / \mathrm{E} 2=83.95 / 82.57)$ than the criteria (80/80). This was due to the fact that the researcher followed the process instructional media development and lesson creation. The researcher examined learners' problems, relevant concept, theory, document, curriculum, psychological principles, and research paper prior to creating and developing the books. In addition, the following five steps of instructional media development process were also employed:

Step 1 - Analysis: The step began with (1) analyzing the pre-service teachers; (2) analyzing the purpose of creating the 
AR books; and (3) analyzing the content used in lettering and calligraphy with parallel pens which is the content from the Educational Technology and Innovation course from the topic titled Hand Lettering Calligraphy with Parallel Pens which comprises Basic Calligraphy; Thai Calligraphy; English Calligraphy; and Arabic Calligraphy.

Step 2 - Design: This step comprised the following elements: (1) Book and print formatting: Before printing, the texts must be clear, the cover must be beautiful and attractive, book size and font size must be appropriate for learners, image and text placement must be harmoniously arranged as opposed to overlapping, and the title must sound appealing; (2) Correct and attractive content: It must not be too easy nor difficult to the target audience; (3) Supplementary images: Ensure that they are colorful and consistent with the content. The images must be accurate and correct while the size must be suitable with the AR book size; and (4) Animation and video: The format and design must be coherent with the content.

Step 3 - Development: It was when to start constructing the AR books by following the plan obtained from the design step. Images and sounds were arranged and merged together. The music and narrative voice were also incorporated. Later, both the AR books and video animations were used to create an augmented reality (AR).

Step 4 - Implement: This step ran a preliminarily test on the constructed media to identify basic errors. The process was conducted involving both small and large group of pre-service teachers.

Step 5 - Assessment: The AR books were assessed for quality by the experts and efficiency by the pre-service teachers. After receiving expert feedback, the AR books were improved as recommended. Therefore, the AR books went through a suitability test, an expert-level quality inspection, and an efficiency evaluation from the pre-service teachers which made them relevant to the objectives, interesting in format, orderly in presentation, and efficient in learning. This was in concert with many of educators which explained that a good development of instructional media comprises of five systematic sequences namely, analysis, design, development, implement, and assessment [9]. A good AR media should be constructed through a research process with content examining and analysis; a lesson design aiming to catch attention e.g. the use of image and video in the lessons; a verification measure; a trial session; and an efficiency evaluation [10]. Similarly to some educators which concluded that the following traits define a good school book: (1) Good printing techniques and layout design: Before printing, the texts must be clear, the cover must be beautiful and attractive, book size and font size must be appropriate for learners, paper quality must be good, book layout must look clean, image and text placement must be harmoniously arranged as opposed to overlapping, and the title must sound appealing; (2) Attractive content: The content must be made interesting and not to be too easy or difficult to the age of the learner. Ensure that the content is correct and the story is plotted in a manner that learners are attracted to follow along. The content length must not be too long or short and it must be beneficial to the learners; and (3) Supplementary images: Ensure that they are colorful and consistent with the content. The images must be accurate and correct while the size must be suitable with the book size [11].

2) The comparative results between the control group (54 pre-service teachers) and experimental (69 pre-service teachers) group in using the AR books on hand lettering calligraphy with parallel pens and the effect on instructional-media production capability revealed the following data: (1) The pre-learning production capability scores of both groups suggested no statistical difference at the .05 significance level; (2) The pre and post learning production capability scores of the control group suggested a statistical difference at the .05 significance level where the post-learning production score was higher than the pre-learning one; (3) The pre and post learning production capability scores of the experimental group suggested a statistical difference at the .05 significance level where the post learning production score was higher than the pre learning one; and (4) The post learning production capability scores of both groups suggested a statistical difference at the .05 significance level where the experimental group scored higher.

This could be because the AR books were used as media in content presentation. With the help of short animation and AR technology, the learning was made sufficiently easy to comprehend. The content was correct and arranged in an orderly manner which made it possible for the pre-service teachers to digest the information and immediately follow through. The content was designed with attention catching emphasis which allowed the pre-service teachers to autonomously and virtually utilize the content improve their skills through a simultaneous visualization and practice. This helps extend the duration of visual memory and the attempt to bring the perception to actual practice as it can keep the pre-service teachers interested, attentive, and enthusiastic to do more. Through trial and error, the more frequent the practice, the more skillful the students become. In addition, the study could simply occurs without location limitation and it can be repeated as desired until the students could overcome a training obstacle and achieve a desirable or optimal result. Moreover, as it is a new type of media, if appropriate teaching strategy is implemented onto the AR, the pre-service teachers would feel intrigue which would then trigger their interests and the eager to learn more. The concept is consistent with some educators which explained that an instructional media that makes the learning easy, can provide learners a joyful experience, foster them with positive attitude, and motivate them to learn and all that further lead to a better learning achievement [12]. AR technology can make an instructional media more interesting and it can stimulate learning enthusiasm. The technology encourages the learners to feel fun and exciting to be exposed to it. In addition, it prevents them to feel bored as they can participate while learning. An instructional media with images, moreover, can enhance the speed and ease of comprehension [13]. It also offers a new perspective to learning. Consistently which suggested that an instructional design that allows learners to participate in actual practice with balance left-right brain hemispheres would encourage the learners to have fun and feel enthusiastic to learn which means it can retain their attention and prevent them from feeling bored. Such efficiency would eventually 
lead to a more successful learning achievement [14].

3) The pre-service teachers demonstrated the highest satisfaction level with a mean score of 4.53 towards the use of the AR books on hand lettering calligraphy with parallel pens and their capability of instructional media production. This was due to the fact that the AR books were presented with interesting images and videos; the AR book covers and format were attractively colorful; each AR book was designed differently but remained consistent under a common theme, and the calligraphy practices can be used for repetitive training. The graphics in AR books were modern and rich of clear, correct, and beautiful. Each video in AR books were consist of graphic, animation, music, to audio narration making. It is well suitable for training and practicing. Moreover, it also encouraged the students to become more eager to learn than traditional methods. It also offered the more autonomous, convenient, enjoyable learning experience that can lead to a better, the more efficient learning outcome. This was in line with some educators mentioned that books that are easy to learn, attractive, and helpful in promoting a better understanding of lessons generally received high satisfaction score [15].

\section{SugGeSTIONS}

The following items are some suggestions the researcher would like to make which would be beneficial in learning management using the augmented reality books on hand lettering calligraphy with parallel pens and the pre-service teachers' capability of instructional media production:

1) Utilization of the research results: The AR books can be utilize for other profession such as graphic designer, illustrator or other interests to develop Hand Lettering Calligraphy with Parallel Pens capability

2) Further Studies: AR books with AR technology on other subjects should incorporate animations and three-dimensional imagery into the presentation so that the students can efficiently and quickly grasp the ideas.

\section{REFERENCES}

[1] S. Thanakorn, Calligraphy and Illustration, Odian Store, Bangkok, 2014.

[2] N. Kanita, Instructional Media: Graphical Work and Method, The Leading Thai Nam Printing House, Songkhla, 1992.

[3] K. Nuttaphong, "Development of a blended learning model based on creative problem solving principles using lateral thinking to enhance creative problem solving abilities for instructional media production of pre-service teachers," Ph.D. Dissertation, Chulalongkorn University, Bangkok, Thailand, 2012.

[4] M. Kidanan, Technology and Communication for Education, Arun Publishing, Bangkok, 2000.

[5] S. Jaruwat, "Condition, problem, demand of instructional media among teachers of islamic private schools in the southern border provinces," Journal of Social Sciences and Humanities.
[6] T. Raksapon, Augmented-Reality Learning Supplementary Media, Thai Wattana Panich, Bangkok, 2010.

[7] M. Billinghurst and A. Dunser. (November 2017). Augmented reality in the classroom. IEEE Computer Society. [Online]. Available: http://ieeexplore.ieee.org/abstract/document/6171143/?anchor=refere nces

[8] Office of Higher Education Commission. (January2018). Statistics on the number of students in education faculties in Thai higher education institutions. [Online]. Available: http://www.info.mua.go.th/information/show_all_statdata_table.php? data_show $=2$

[9] N. Jaitip, Methodology to E-Instructional Design, Chulalongkorn University Press, Bangkok, 2007.

[10] S. Manop and S. Paitoon, "Development of augmented reality on science for schools with lower achievement standards, Nakhonnayok primary educational service area," Educational Technology and Media Convergence Journal, Thaksin University, vol. 1, no. 2, pp. 87-95, 2014.

[11] C. Pornchan et al., Writing and Publishing Books for Youth, Ton Aor Grammy Co., Ltd., Bangkok, 2000.

[12] P. Porntip, "Effecting augmented reality code of Chinese vocabularies lesson for grade 3 students at Tessaban 2 Wattaninarasamosorn School," M.Ed. Thesis, Prince of Songkla University, Songkla, Thailand, 2016.

[13] U. Nattawee and W. Nawapon. (September 2017). Applying augmented reality technology to facilitate learning: English alphabets from A-Z. [Online]. Available: http://www.artymix.com/files/NCIT_Nattavee_Navapon.pdf

[14] W. Usa and B. Tassanee. "The effects of the 4MAT cycle learning activities on the body system: Topic for Mathayomsuksa II students," M.Ed. Thesis, Khon Kaen University, Khon Kaen, Thailand, 2010.

[15] P. Petcharapan and N. Chatchawin, "The development of 3D supplementary book using augmented reality technology "solar system," Science and Technology RMUTT Journal, vol. 6, no. 2, pp $48-57,2016$

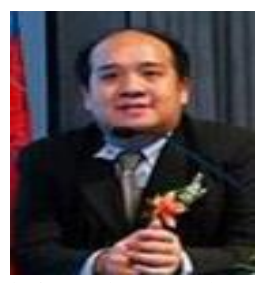

Nuttaphong Kanchanachaya was born on February 27, 1978 in Bangkok, Thailand. He received B.Ed. in social and computer teaching methodology and the M.Ed. in audio-visual education and the Ph.D. in educational communications and technology from Faculty of Education, Chulalongkorn University, Thailand. He also the assistance dean for technology and informatics, Faculty of Education, Prince of Songkla University, Thailand. He has been engaged in teaching and research in e-learning, instructional media production, photography, educational technology and innovation in many years. He is currently instructor at the Department of Educational Technology, Faculty of Education, Prince of Songkla University, Thailand.

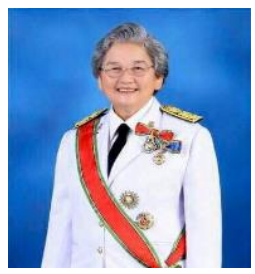

Kanita Nitjarunkul was born on March 5, 1952 in Songkla, Thailand. She received the B.Ed. in secondary education, Srinakarintraviroj University and the M.Ed. in educational media and the Ph.D. in curriculum \& instruction: educational technology, University of Missouri, United State of America. She also is the head of the curriculum of teaching profession, Faculty of Education, Prince of Songkla

University, Thailand.

She has been engaged in teaching and research in e-learning, instructional media production, photography, educational technology and innovation in many years. She is currently associate profeesor, the Department of Educational Technology, Faculty of Education, Prince of Songkla University, Thailand. 